ESTUDIOS 



\title{
CONTROL JUDICIAL DE LA DISCRECIONALIDAD TÉCNICA: ERROR MANIFIESTO, INMEDIACIÓN, SANA CRÍTICA
}

\author{
JUAN IGARTUA SALAVERRÍA ${ }^{1}$ \\ Universidad del País Vasco \\ juan.igartua@ehu.eus
}

Cómo citar/Citation

Igartua Salaverría, J. (2017).

Control judicial de la discrecionalidad técnica: error manifiesto, inmediación, sana crítica.

Revista de Administración Pública, 204, 11 -39.

doi: https://doi.org/10.18042/cepc/rap.204.01

\section{Resumen}

Al hilo de su comentario sobre una STS, un reconocido administrativista defiende que el control judicial de la discrecionalidad técnica se limite a censurar únicamente el «error manifiesto». Descartado este, las posibles discrepancias se reducen a la pugna entre distintos pareceres técnicos en la que la Administración lleva las de ganar, según la jurisprudencia de los altos tribunales. Pero es que, además, el órgano administrativo está en una situación ventajosa, más próxima a la realidad, pues ha gestionado directamente todo el proceso selectivo; en cambio, el tribunal de justicia solo cuenta con la versión ofrecida por las partes. Y a ello debe añadirse que el órgano administrativo, al estar compuesto por miembros especializados, ofrece más garantías de acierto que un tribunal con sus genéricas reglas de la sana crítica. Estos tres temas serán sometidos a discusión en el presente trabajo.

\section{Palabras clave}

Discrecionalidad técnica; error manifiesto; inmediación; control judicial; sana crítica.

1 Catedrático emérito de Filosofía del Derecho. 


\begin{abstract}
In the wake of his commentary on a STS, a well-known administrativist argues that judicial control of technical discretion should be limited to censoring only "manifest error". Once this is ruled out, possible discrepancies are reduced to the struggle between different technical opinions in which the Administration has the upper hand, according to the jurisprudence of the high courts. But, in addition, the administrative body is in an advantageous position, closer to reality, because it has directly managed the entire selection process; in contrast, the court of justice has only the version offered by the parties. And to this must be added that the administrative body, being composed of specialized members, offers more guarantees of discernment success than a court with its generic rules of sound criticism. These three themes will be discussed in this paper.
\end{abstract}

\title{
Keywords
}

Technical discretion; manifest error; immediacy; judicial control; sound criticism. 


\section{SUMARIO}

I. INTRODUCCIÓN: 1. Poniéndonos al tanto. 2. ¿̇Esperanza truncada? II. ERROR «PATENTE»O «MANIFIESTO»: 1. ¿QQué juego dio el «error manifiesto»? 2. Ambigüedad de "error manifiesto». 3. "Error manifiesto» ¿̇sobre qué? III. LA SINGULAR E IRRECUPERABLE «INMEDIACIÓN»: 1. Una versión no impresionista de la «inmediación», pero... 2. 2̇lnsuperable relativismo? 3. A vueltas, una vez más, con el «error». 4. ¿̇Nos hemos extraviado? IV. UN CONTROL ESPECÍFICO: ¿̇QQUÉ»Y "CÓMO» CONTROLAR?: 1. ¿̇Qué se controla? La motivación. 2. ¿̇Cómo se controla? El papel de la «sana crítica».

\section{INTRODUCCIÓN}

A algún maldito despiste personal ${ }^{2}$ debo achacar que no reparara cuando debí en un artículo que, por materia y autoría ${ }^{3}$, me era de particular interés ${ }^{4}$. Pero, por fortuna, el texto mantiene la actualidad del primer día. De manera que he podido aprovechar su lectura como lo hubiera hecho hace un par de

2 Pues desde que retomé la preocupación por el tema ( $c f r$. J. Igartua Salaverría (2013), «Discrepancias sobre el control de la discrecionalidad técnica», Jueces para la Democracia, 76, págs. 10-20) no perdía de vista cuanto sobre el particular escribieran al menos los autores de quienes siempre se aprende (y mucho). Así, no se me escapó el artículo publicado en esta misma revista (Fernández (2015), «La discrecionalidad técnica: un viejo fantasma que se desvanece», Revista de Administración Pública, 196, págs. 211-227) con una orientación de fondo que confortaba mis puntos de vista, aunque contraria a los del trabajo que aquí comentaré. Deploro haber topado con este último tan a destiempo.

3 Se significó como uno de los principales protagonistas del tenso pero fecundo debate (sobre el control judicial de la discrecionalidad administrativa, precisamente) entre administrativistas de mucha nota a primeros de los noventa del siglo pasado, y de cuyos frutos algunos pretendimos sacar alguna rentabilidad.

4 Me refiero a M. Sánchez Morón (2015), «Sobre la discrecionalidad técnica y la sana crítica (Comentario a la sentencia de la Sala de lo Contencioso-Administrativo del Tribunal Supremo, Sección 7a , de 16 de diciembre de 2014, dictada en recurso de casación 3157/2013)», Revista de Administración Pública, 197, págs. 209-222. 
ańos o como si la redacción del «Comentario» (que comento) fuera de hoy mismo. Razón por la que tampoco estimo fuera de tiempo formular, aun a estas alturas, alguna que otra observación colateral y/o discrepante.

\section{PONIÉNDONOS AL TANTO}

En la STS cuyo análisis se acomete en el «Comentario» que analizaré, la Sección $7^{a}$ de la Sala $3^{a}$ examinaba un recurso contra una resolución del Tribunal Superior de Justicia del Principado de Asturias (Sala de lo Contencioso-Administrativo) desestimatoria de la impugnación presentada por una concursante-opositora a una plaza de Medicina Intensiva en el Servicio de Salud de aquella comunidad autónoma.

El origen de su queja era este: en la segunda prueba (solución por escrito de dos casos prácticos y posterior lectura ante la Comisión calificadora), que era eliminatoria, la recurrente obtuvo una puntuación inferior a la requerida. La afectada solicitó una revisión del examen ante la Comisión examinadora, la cual le mostró el ejercicio y le informó del porqué de la calificación. La recurrente planteó un recurso de alzada contra el acuerdo de la Comisión (aduciendo "error manifiesto" $\mathrm{y}$ "falta de motivación»), pero que fue desestimado. Volvió a la carga formulando un recurso contencioso-administrativo ante el TSJ de Asturias y corrió la misma suerte. Finalmente, impugnó la sentencia del citado Tribunal ante la Sala $3^{a}$ del TS, cuya resolución —en lo que estrictamente ahora interesa - negó que la prueba pericial aportada a favor de la recurrente hubiera demostrado que la Comisión incurrió en "error patente» (condición indispensable, según la jurisprudencia, para anular una decisión adoptada en el ejercicio de la "discrecionalidad técnica»), si bien uno de los magistrados de la Sala exteriorizó su disenso al respecto en un voto particular. De esta historia (en realidad más compleja que la aquí referida), Sánchez Morón entresacó en su "Comentario» los aspectos más enjundiosos en orden a retomar una polémica (la relativa al control judicial de la "discrecionalidad técnica») que tiene visos de nunca acabar, aunque con la esperanza de que los desacuerdos doctrinales puedan venir a menos si descendemos del cielo de la «teoría» a la tierra de la "práctica» judicial concreta. Pues esta permitirá conferir un perfil más definido a cuestiones tan medulares como: ¿qué ha de entenderse por «error manifiesto»? ¿Están acaso en igualdad de condiciones para estimar el acierto de una decisión técnica, por un lado, el órgano administrativo involucrado en la misma (no solo provisto de los saberes específicos requeridos, sino, además, conocedor de primera mano de cuantas informaciones son pertinentes al efecto) y, por el otro, un tribunal de justicia (sin la cualificación técnico-científica exigible en razón de la materia $y$, en cuanto ajeno a la decisión, disponiendo solo de un conocimiento de 
referencia de cuanto acaecido en otra sede)? ¿Cómo puede controlarse razonablemente la corrección de una decisión adoptada en base a criterios técnico-científicos si solo se maneja una criteriología ni técnica ni científica, como es la que corresponde a las «reglas de la sana crítica»? Cuestiones estas que explícitamente emergen en el texto de tan cualificado administrativista (catedrático en la Universidad de Alcalá, como se sabe).

\section{2. ¿̇ESPERANZA TRUNCADA?}

Frente a la generalizada propensión de la doctrina académica a desentenderse de la indumentaria concreta que presentan los casos litigiosos y, en su lugar, emprender el vuelo por el anchuroso espacio de planteamientos globales (sobre el control de la "discrecionalidad técnica», en lo que aquí toca), nuestro autor persigue — «a la luz de una sentencia interesante»— una «finalidad práctica», «modesta pero espero que no inútil», por cuanto que «en la solución de los casos de la vida real, las teorías jurídicas se enfrentan a la prueba del nueve» ${ }^{5}$.

Pues bien, la referida sentencia no ha sido nada complaciente con las expectativas del administrativista (y, de paso, tampoco con las nuestras). En efecto, asombra ya de entrada que por ningún lado se describa en la STS el rechazado "error manifiesto», pieza sobre la que pivota este contencioso. ¿Cómo apreciar, entonces, si es o no «manifiesto» cuando ni siquiera sabemos en qué consiste el presunto «error»? Y conste que la omisión no es imputable al comentarista sino al propio tribunal sentenciador; con la agravante ańadida de que precisamente en torno a ese particular gira el desacuerdo dentro de la Sala misma sobre el punto decisivo (la mayoría descarta el "error manifiesto» mientras que el firmante del voto particular estima que sí lo hay) y que será determinante para el signo de la resolución (desfavorable a la recurrente, esta vez). Sin embargo, leída la sentencia en su integridad, así como el voto particular, continuamos sin enterarnos de nada. Desconocemos por entero cuál fue el objeto preciso de la discusión.

Así las cosas, ¿¿tiene algún sentido preguntarse por las ventajas que, sobre tan ignoto asunto, aportaba la inmediación para estimar con fundamento si había o no "error» y si este era o no "manifiesto»? E, igualmente, ¿es juicioso ponerse a calibrar la capacidad de la «sana crítica» en orden a detectar un hipotético «error» del que ignoramos en qué consiste?

En suma: ¿de qué nos aprovecha finalmente la —en apariencia - tan prometedora sentencia? A lo sumo, de leńa para alimentar (no de agua para apagar) el fuego de la polémica entre los teóricos. Ocasión habrá, si no, de

5 Sánchez Morón (2015: 210). 
comprobar cuál es el tipo de partido que de aquella saca su comentarista: un manojo de consideraciones generalistas, estimulantes sin duda, pero desenganchadas de la singularidad del caso enjuiciado. No obstante, merecerán atención muy preferente. $\mathrm{Y}$ a eso, precisamente, se destina lo que sigue.

Bien es verdad que sobre el texto de Sánchez Morón aletean algunos problemas que, por designio consciente de su autor, no terminan de anidar en aquél (por ejemplo, el relativo a la discutida identificación de la «discrecionalidad técnica de los órganos de selección, llámese como se llame» ${ }^{6}$ como contradistinta de la interpretación de "conceptos indeterminados») y, por tanto, tampoco ahora serán tomados en cuenta ${ }^{7}$.

\section{ERROR «PATENTE»O «MANIFIESTO»}

No sucede lo mismo, en cambio, con el motivo del «error patente o manifiesto", el único que hasta el momento permitía a los Tribunales adentrarse en el «núcleo material del juicio técnico [...] para comprobar si es técnicamente correcto o no y, en su caso, anularlo o sustituirlo por una resolución propia en contrario». Pero para ello era preciso que «dicho juicio técnico fuera manifiestamente erróneo, como, por ejemplo, cuando se aprecia con criterios de lógica elemental, que no requieren saberes especializados, que un órgano selectivo ha puntuado como incorrecta una respuesta que no lo era, o viceversa» ${ }^{8}$.

\section{1. ¿̇QUÉ JUEGO DIO EL «ERROR MANIFIESTO»?}

Pues bien, en lo que hace al caso, nuestro administrativista nos refiere que el TSJ asturiano «declaró admisible la prueba pericial propuesta por la actora»,

6 Sánchez Morón (2015: 222).

7 Lo que no implica restar relevancia a una cuestión que no es meramente nominal sino, sobre todo, conceptual y con inevitables consecuencias. De modo que vendría bien someter a revisión — para confirmar o para desterrar o para modificar - la categoría jurídica misma de "discrecionalidad técnica». Al respecto es recomendable la lectura de I. Lasagabaster (2016), "Sobre la discrecionalidad técnica», en I. Ordeñana y M. Uriarte (dirs.), Justicia en tiempos de crisis, Bilbao: Servicio Editorial Universidad del País Vasco, págs. 295-310. Y en fecha más reciente, el magistrado de la Sala 3a , J. J. Suay Rincón, en su voto particular (concurrente) a la STS 1136/2017, de 27 de junio, ha cuestionado que la alegada «discrecionalidad técnica» en el nombramiento para un cargo judicial sea asimilable a la discrecionalidad administrativa, defendiendo por contra su adscripción en el orbe de los «conceptos jurídicos indeterminados», con la consiguiente modificación en la manera de concebir su control judicial.

8 Sánchez Morón (2015: 214). 
si bien «concluyó que se trataba de una prueba insuficiente para desvirtuar el criterio del órgano de valoración, pues no ponía de relieve que éste hubiera incurrido en error patente y no expresaba más que la opinión de una especialista frente a la de los miembros que componían el tribunal calificador del proceso selectivo». Ahora bien, el Tribunal Supremo — prosigue el autor- estimará que «dicha sentencia debe ser casada» por valorar «de manera tan genérica la insuficiencia de la prueba pericial aportada al proceso por la recurrente». Y aprovechará la ocasión para, en la nueva resolución, complementar con «otras consideraciones» la «doctrina jurisprudencial elaborada» hasta el momento?

De entre las consideraciones complementarias, agrupadas en el FD $6^{\circ}$ de la STS, entresacaré solo las imprescindibles para mi propósito: a) «Un órgano jurisdiccional carece de conocimientos específicos para emitir un definitivo dictamen, desde una evaluación puramente técnica, que dirima lo que sean meras diferencias de criterio exteriorizadas por los expertos». b) «La solvencia técnica y neutralidad que caracteriza a los órganos calificadores impone respetar su dictamen mientras no conste de manera inequívoca y patente que incurre en error técnico». c) La prueba pericial «no puede limitarse a revelar una simple opinión técnica diferente, sino tiene que incorporar elementos que permitan al tribunal de justicia formar con total seguridad su convicción sobre esa clase de error». d) Para ello será necesario que «la pericia propuesta identifique de manera precisa y clara los concretos puntos del desacierto técnico que advierte en el dictamen del órgano calificador»; y que «señale fuentes técnicas de reconocido prestigio en la materia de que se trate que, respecto de esos concretos puntos, hayan puesto de manifiesto que son mayoritariamente valorados en el ámbito científico como expresivos de un evidente e inequívoco error».

Una vez sentadas tales condiciones, la Sala aprecia (FD $8^{\circ}$ ) en el informe pericial un «distinto parecer técnico» «en relación con los criterios y soluciones elegidos como correctos por el tribunal calificador, pero no que dichas opciones de este último hayan sido mayoritariamente considerados por la comunidad científica como errores inaceptables o evidentes» (sin otra justificación). Apreciación que, sin embargo, contrasta con la que el magistrado disidente manifestará en el punto $3^{\circ}$ de su voto particular (VP) al proclamar que «a mi juicio la pericial que acompañó el actor es lo suficientemente esclarecedora del acierto del recurrente» (sin más explicación).

Los términos de este desacuerdo intracolegial solo han dejado una cosa clara: lo único manifiesto es la deficiente motivación — la de la mayoría y la minoría - cuando se pronuncian acerca de si hay o no un «error manifiesto». La oscuridad reina sobre todo lo demás. Si bien, siquiera a ciegas, quizá cabría

9 Sánchez Morón (2015: 215-216). 
aventurar una hipótesis: que los unos y el otro no hablan de lo mismo. Quede así, de momento.

Tampoco se crea que la expresión misma de «error manifiesto» es de unívoco significado: ni sobre el papel — por supuesto- ni tampoco en su uso práctico. Por ello, convendría encarar primero este obstáculo preliminar.

\section{AMBIGÜEDAD DE «ERROR MANIFIESTO»}

Un provisional y breve (pero suficiente) censo de los distintos sentidos de "error manifiesto" nos procura el resultado siguiente. Por «error manifiesto" cabe entender al menos: a) el error que se detecta ya a primera vista; b) el error que se detecta mediante criterios de lógica elemental (sin recurrir a saberes especializados); c) el error que se detecta con fundamento en los saberes correspondientes (si es técnico, con los conocimientos técnicos adecuados); d) el error detectado con tal rotundidad que no admite discusión.

Y el elenco de significados se dispararía si combinamos entre sí esos cuatro iniciales (es decir: por ejemplo, «error manifiesto» es el que se detecta a primera vista con la sola ayuda de la lógica elemental; "error manifiesto» es el que se detecta a primera vista y no admite discusión; «error manifiesto» es el que se detecta a primera vista mediante el adecuado aparato conceptual; «error manifiesto» es el que se detecta mediante el adecuado aparato conceptual y no admite discusión...; y así sucesivamente).

Pero no es necesario ahora navegar en mar tan abierto. Bastan unos pocos descartes para no quedar a la deriva. En concreto y para empezar: tanto en la STS como en el VP se prescinde de la primera condición (que el «error» deba manifestarse icto oculi). De otro modo, sería inadmisible cualquier prueba al respecto por cuanto superflua (contraria por tanto al principio de «economía procesal»); lo que no ha sucedido en esta ocasión (se admitió sin protestas una prueba pericial). De manera que el carácter «manifiesto» del error ha de referirse no a su aparecer sino a su ser ${ }^{10}$.

En segundo lugar, la pacífica admisión de un elemento de prueba de naturaleza pericial (y no de mera «lógica elemental» ${ }^{11}$ ) deja a las claras que la Sala entera (mayoría y minoría) concuerda en que el aparato técnico-conceptual adecuado para identificar el "error» ha de estar en consonancia con la específica actividad que se controla. Una opción distinta hubiera sido encima, más que irrazonable, una desvergonzada parodia.

10 Puntualización que se toma de F. M. Iacoviello (1997), La motivazione della sentenza penale e il suo controllo in cassazione, Milano: Giuffrè, pág. 299.

11 A diferencia de lo que en un pasado bastante reciente entendía el TS, según se desprende de Sánchez Morón (2015: 214, nota 17). 
En tercer término, todo induce a pensar, pese a la desinformación que nos embarga, que el disenso dentro de la Sala no versa sobre la rotundidad exigible en principio al «error» (para tenerlo por "manifiesto») sino sobre si ahora ese era o no el caso. En efecto, no hay rastro de divergencias sobre lo primero entre la STS y el VP. En cambio, apurando mucho la atención, se perciben pistas que conducen a conjeturar lo segundo; con el evidente riesgo de equivocarnos, claro está. Pero, aun así, no será empeño baldío intentarlo porque dará pie al despunte de un problema — creo que - aún por explorar. Aguardemos un poco a ver cómo.

\section{3. «ERROR MANIFIESTO» ¿̇SOBRE QUÉ?}

Ya se mencionó, en su momento, la frontal oposición entre la STS y el VP en torno a si hubo o no "error manifiesto» en esta ocasión. Estaba de por medio la valoración del informe pericial aportado por la recurrente. Recordémoslo:

A. La mayoría de la Sala (según refleja la STS) lo miró por uno de sus ángulos (que proyectaba su visión hacia la comisión examinadora), para constatar que el perito había equivocado el tiro, porque no demostraba que fueran "calificadas por la mayoría o la generalidad de la comunidad científica como un error que sea inequívoco, claro y patente» tanto «las razones que [el tribunal calificador] aprobó previamente como criterio de calificación de las preguntas que fueron formuladas», como tampoco «las razones que luego ofreció para valorar la concreta puntuación aplicada» (FD 8º).

De su lado, el magistrado disidente optó por una diversa perspectiva (que apuntaba a si eran o no correctas las respuestas dadas por la candidata examinada), concluyendo que el informe avalaba el acierto de la recurrente en sus respuestas $\left(\mathrm{VP} 3^{\circ}\right)$.

B. Del texto de la STS parece colegirse que el perito, tras manifestar «un desacuerdo o discrepancia técnica con el tribunal calificador en relación con las respuestas que este aprobó previamente» y con «las razones que luego ofreció para valorar la concreta puntuación aplicada», pasó a defender como acertadas otras «respuestas» y "razones» alternativas, a la luz de las cuales el examen debía considerarse superado. Desde luego, en la STS no hay rastro que desautorice esta hipotética reconstrucción mía de lo sucedido.

$\mathrm{Ni}$ por lo más remoto la Sala afirmaba que fueran indefendibles los argumentos alegados por el perito en favor de la candidata. Solo reconocía que con esos no alcanzaba para demostrar que la grille selectora elaborada por el tribunal examinador (y su posterior aplicación al caso) contenía algún error que fuera «inequívoco, claro y patente»; pero la Sala no excluía que el modelo 
de examen usado por el tribunal como cotejo corrector de las respuestas podía quedar al menos razonablemente relativizado al confrontarse con el informe pericial. Entonces, sale disparada esta pregunta de aspecto retorcido (¡lo siento!): ¿por qué no sería «error manifiesto» estimar como equivocada una respuesta que «la mayoría o la generalidad de la comunidad científica no califica como error» simplemente por no ajustarse a una respuesta que la Comisión ha canonizado, pero cuya credencial tampoco va más allá de no haber sido apreciada como errónea por la mayoría o generalidad de la comunidad científica?

Aun a riesgo de salirme de madre, pero obligado por el deplorable vacío argumental de esta STS y de su VP anejo, echaré mano de un ejemplo (no tan imaginario ${ }^{12}$ ) con el que persigo ilustrar, mal que bien, lo que quizás no haya atinado yo a expresar debidamente. Pongamos que en un concurso convocado por la Comunidad de Madrid para la provisión de una plaza de guardabosques, se pregunta a los candidatos en qué río de esa Comunidad puede encontrarse el calandino (un tipo de pez). En el modelo de examen que maneja la Comisión, figura el río Henares como respuesta correcta. Uno de los candidatos señala en su ejercicio el río Jarama. Error. No obstante, en su ulterior demanda adjunta una publicación de la Consejería de Medio Ambiente de la citada Comunidad donde también se identifica al río Jarama como hábitat del calandino. El opúsculo de la Consejería no demuestra que constituya un desacierto patente la respuesta que figura en el modelo de examen, pero evidencia que la Comisión ha incurrido en un error manifiesto al manejarla como si fuera la única respuesta válida.

¿Sería asimilable a la situación descrita — con las inevitables adaptaciones ¡claro! - el contencioso que tocaba resolver esta vez a la Sala 3 a? Imposible saberlo. Instalados en la inopia, como nos han dejado la STS y el VP, no queda otra que encogerse de hombros. No obstante, tampoco se ha perdido el tiempo. Porque, inopinadamente, se abre la ventana hacia una nueva consideración, no del todo ociosa.

C. En efecto, convendría subrayar que no todas las circunstancias comúnmente consideradas de "discrecionalidad técnica» están cortadas por el mismo patrón. No siempre que un órgano administrativo actúa conforme a saberes técnico-científicos afectados por algún margen de opinabilidad, lo hace de manera «discrecional» (en sentido clásico).

Una situación en la que se hace imprescindible optar difiere de otra en la que no es necesario hacerlo. A veces, como en la provisión de una única plaza, ante dos alternativas razonables, es ineludible elegir una o la otra (no se puede

12 Pues reproduce, con algunas modificaciones, un caso resuelto por el TS en el 2010. Para detalles, cfr. Lasagabaster (2016: 307). 
proponer a un candidato y a otro al mismo tiempo; y quizás no incurrirá en error manifiesto quien prefiera al primero sobre el segundo, o al revés). Otras, en cambio, no; como en la corrección de unos exámenes (así cabrá calificar de correctas, contemporáneamente, dos soluciones distintas pero razonables a un mismo problema; e incurrirá en error manifiesto el examinador que tache como incorrecta cualesquiera de ambas respuestas).

Y no ha de pasarse por alto que, en esta ocasión, la Comisión — aun en el marco de un concurso que al final se dirimiera optando por una candidatura frente a otras - afrontaba la corrección de un examen (un caso práctico) al que debía asignar la puntuación debida (fuera esta mayor o igual o menor a la obtenida por cualquier concursante; no había por qué preferir).

\section{LA SINGULAR E IRRECUPERABLE «INMEDIACIÓN»}

Tiene su miga que, dejando de lado «la disputa teórica o conceptual», y para «reflexionar sobre cuál es la solución más correcta en casos como el que se plantea y en términos de justicia material», el catedrático de Alcalá evoque su experiencia personal como participante en escenarios similares al de ahora (es decir, en «tribunales de selección para el acceso a la función pública») $)^{13}$, porque ello le dará pie a subrayar el papel de la «inmediación» (aunque sea palabra que él no usa) en la valoración de las pruebas selectivas.

Constata el administrativista que «seleccionar no es tarea fácil, y cuando entre los candidatos en un proceso selectivo no se advierten diferencias sensibles de conocimiento, decidir a favor de unos u otros tiene muchas veces algo de aleatoriedad, ya que se basa en matices o detalles prefigurados como relevantes por quien selecciona». Y agrega: "Creo tener algunas cosas claras. Primero, que nunca he estado seguro de que diera mi voto al mejor candidato para desempeñar un puesto de funcionario, sino tan solo a quien demostraba mayores conocimientos de la materia objeto de cada prueba. Segundo, que ni siquiera puedo afirmar que haya votado a quien realmente tuviera más conocimientos, sino a quien en la forma y en el contenido de la exposición se aproximaba más a lo que yo personalmente consideraba que debía exponerse. Muy probablemente, de ser otro el responsable de la selección, el resultado hubiera sido diferente, pues, salvo si se advierten ostensibles diferencias entre los candidatos, todo depende de quién valora sus ejercicios» ${ }^{14}$.

Pero el autor se apresura a puntualizar que «a efectos del control judicial se puede reproducir el argumento»; porque también «el juez ha de valorar esas

13 Sánchez Morón (2015: 219).

14 Sánchez Morón (2015: 219-220). 
pruebas y expresar un juicio personal o subjetivo sobre ellas»; lo contrario «sería tanto como sostener la infalibilidad judicial $»^{15}$. De modo que, por lo pronto, un tribunal de justicia no ostenta mejores títulos que un órgano administrativo para fiscalizar las eventuales equivocaciones que este pueda cometer.

Más todavía. Está incluso en peores condiciones. Y no solo porque, a diferencia de los jueces — personas que en cuanto a preparación técnica forman parte del común de la gente-, "el órgano de selección se componga de especialistas en la materia de que se trate», sino porque "dicho órgano de selección se encuentra más próximo a la realidad, ya que ha tramitado directamente todo el proceso selectivo y sus integrantes han podido valorar personal y comparativamente a todos los candidatos». Por el contrario, «los elementos de juicio a disposición del órgano judicial son los que en el proceso se representan y [...] eso supone que, de hecho, los jueces no fallan sino en virtud de opiniones ajenas, sean las de los abogados de las partes, sean las de los peritos. Probablemente es más fácil equivocarse así». Y nada digamos si, por añadidura, "como en el caso comentado, [se trata de] una prueba pericial [...] que expone la opinión fundada de quien la emite, no directamente sobre el proceso selectivo, sino sobre lo que los otros han resuelto al respecto» ${ }^{16}$. O sea, para entendernos: ni siquiera el relato de un participante (discurso de primer grado) sino el análisis de aquel relato (metadiscurso). Qué lejos de la realidad, ¿no? Eso parece a primera vista.

\section{UNA VERSIÓN NO IMPRESIONISTA DE LA «INMEDIACIÓN», PERO...}

En su día, me sorprendió, por considerarla — ¿equivocadamente? - fuera de sitio, la alusión al fenómeno de la «inmediación» en un envite similar al de ahora (entonces, un controvertido nombramiento judicial) y por partida doble: una vez en un VP a la STS que anulaba el nombramiento ${ }^{17}$, y la otra en el Acuerdo del CGPJ que volvía a nombrar al mismo candidato ${ }^{18}$.

Ganas daban de embarcarse en un discurso contra las pretextuosas menciones a la «inmediación» para —en su nombre- amparar un tropel de

15 Sánchez Morón (2015: 220).

16 Sánchez Morón (2015: 220-221).

17 Extrañeza que expresé y argumenté en mi comentario J. Igartua Salaverría (2016), «¿Avasalla” la Sala 3a del Tribunal Supremo al Consejo General del Poder Judicial? (De nuevo sobre el control judicial de la discrecionalidad)", Revista Vasca de Administración Pública, 106, págs. 217-245 (págs. 238-240).

18 Razonando mi perplejidad al respecto en J. Igartua Salaverría (2016), «El CGPJ reitera un nombramiento anulado por la Sala $3^{\mathrm{a}}$ (défaillances en su nueva argumentación)», Diario La Ley, 8864, págs. 1-13 (págs. 7-9). 
arbitrariedades ${ }^{19}$. Pero el realismo de nuestro administrativista, persona experimentada en tareas de selección, obliga a mayor cautela y a hilar más fino:

A. Vayan, con carácter preliminar, un puñado de convenciones que hoy día gozan de buena acogida en la teoría jurídica más actualizada ${ }^{20}$; arrancando con una que jamás ha sido discutida, a saber: que en una intercomunicación (por ejemplo, en una declaración procesal), se mezclan informaciones verbales (palabras) con otras no verbales (gestos, muecas, miradas, etc.), perceptibles solo por quienes están allí presentes. Ahora bien —a partir de ahí- ello no impide que los signos no verbales puedan ser verbalizados (descritos con palabras) y solo estos contarán en aquellas decisiones institucionales (sentencias de tribunales, acuerdos de órganos administrativos, etc.) sujetas a una motivación obligatoria y sometidas a control. Lo que importa de la inmediación es, por tanto, la información controlable que en ella se produce y no la ingobernable impresión que genera en la subjetividad del decisor ${ }^{21}$. La inmediación es un instrumento para captar elementos efectivamente observables y describibles, los cuales serán, después, objeto de valoración racional explícita (el titubeo, la inseguridad en las respuestas, la tartamudez, etc., son datos a valorar, no criterios para valorar). Es decir, con esas aportaciones informativas termina el protagonismo de la inmediación; a partir de ahí, entrará en escena la elaboración racional del decisor. Pero, en tanto que la inmediación proporciona un plus de información, habrá de obligar como justa correspondencia a una motivación más rica; es decir, lo contrario de lo que se acostumbra (a decir y hacer), dejando de ser una técnica para conocer más y convirtiéndose ilegítimamente en un cheque en blanco para motivar menos (y de paso proteger al decisor de los rigores del control).

19 Por ejemplo, en lo que respecta a la jurisdicción penal, es muy provechosa la lectura de las páginas que "contra la mística de la inmediación» escribe P. Andrés Ibánez (2015), Tercero en discordia. Jurisdicción y juez del Estado constitucional, Madrid: Trotta, págs. 272-277.

20 Muy bien sintetizada por C. de Miranda Vázquez (2014), «El mito de la influencia de la inmediación judicial en la valoración de la prueba personal: una revisión crítica», Justicia. Revista de Derecho Procesal, 2014, 2, págs. 339-371.

21 Si el decisor se deja guiar por una «impresión» (subjetiva, por tanto intransferible) cierra la posibilidad de motivar su decisión. Eso supone un ataque directo al derecho del administrado a un recurso eficaz. En efecto, si algo hizo mella en el decisor, al administrado habrá que darle información sobre ello: primero, para evitar que el decisor se escude en algo que en realidad no existió o, si existió, quizás interpretó mal; y, segundo, para que el administrado sepa por qué ese dato tiene tal incidencia en una decisión que le afecta. 
B. Bien es verdad que estos preámbulos teórico-metodológicos son solo en parte propicios para aproximarme a la experiencia autobiográfica que narra el profesor de Alcalá. De un lado, se observa, sí, que este acentúa la determinante influencia de la distinta «opinión de quien valora» en cada caso (opinión subjetiva, por tanto), al punto de que — refiriéndose a sí mismo- «ni siquiera puedo afirmar que haya votado a quien realmente tuviera más conocimientos, sino a quien en la forma y en el contenido de la exposición se aproximaba más a lo que yo personalmente consideraba que debía exponerse» [cursivas mías]. Pero, de otro, parece que aquí la «inmediación» no actúa de manera apabullante, provocando e imponiendo un convencimiento por encima de la voluntad de quien en ella se ve comprometido (al estilo de una inefable «íntima convicción"), sino conforme a un plan personal reflexivo (es decir, fruto de la consideración) y debido (o sea, sentido como de obligado seguimiento).

Así las cosas, frente a la vorágine de una asilvestrada «inmediación» (imagen a la que nos ha habituado la literatura procesalista), encontramos en nuestro autor un uso civilizado y racionalizado de la misma, que permite identificar en una situación intercomunicativa aquellos elementos de forma y de contenido (tanto verbales como no verbales) que el decisor toma en consideración por las razones que él (pero solo él) cree debidas. ¿Qué se ha ganado? No demasiado, creo.

\section{2. i̇INSUPERABLE RELATIVISMO?}

¿Para qué esmerarse en razonar la decisión si, total, «muy probablemente, de ser otro el responsable de la selección el resultado hubiera sido diferente»? Basta con que en la «singularizada aplicación de los criterios» — predeterminados por la autoridad normativa- «a tener en cuenta en la valoración», no se haya incurrido «en algún tipo de parcialidad o en un error patente, craso, palmario». "Otra cosa es asegurar el acierto» ${ }^{22}$.

Resulta preocupante el escepticismo — mezcla de resignación («jesto es lo que hay!», se estila decir) y deportividad («hoy hemos perdido, mañana ganaremos, viva la rumba del cańón!», solía cantarse)— que destila este planteamiento, aunque a la persona afectada por la decisión —obtener una plaza o quedarse sin ella—, sin duda, le parezca de un irritante conformismo. Porque la motivación de un nombramiento apunta precisamente a eso, a «asegurar el acierto» de la decisión; no a exteriorizar lo que "personalmente consideraba» el decisor ${ }^{23}$. Lo cual demanda un paréntesis aclaratorio:

22 Sánchez Morón (2015: 220).

23 En otras palabras: «Motivar implica, antes que una comunicación del conocimiento, un saber compartido o compartible» (F. M. Iacoviello (2000), «Motivazione della 
A. Hay dos concepciones principales de la «motivación» (una ya en franca regresión en el plano teórico) que se disputan el protagonismo en la práctica y también en el escenario de la doctrina jurídica. La primera centra su atención en el decisor (marcándose como objetivo describir el itinerario recorrido por aquel para llegar a la decisión); la segunda pone el foco sobre la decisión en primer término (con objeto de argumentar por qué esa y no otra es la correcta). En la primera, la motivación sirve para que el decisor explique por qué ha tomado él esa decisión; en la segunda, para que justifique por qué es justa la decisión tomada y no otra. O sea, en la primera, la motivación tiene por objetivo exteriorizar ante los destinatarios de la decisión los personales motivos del decisor; en la segunda, la de obligar al decisor a justificarse ante aquellos por la decisión adoptada con razones intersubjetivamente preferibles. La primera deja traslucir, por tanto, una impostación autocrática del poder que se ejerce; en la segunda transpira la función democrática de la motivación, entendida como rendición de cuentas del poder ejercido y sometimiento del mismo al control de sus destinatarios (y de las instancias que correspondan).

B. Huelga insistir, por de sobra sabido, que no todos los elementos de "forma» y de "contenido» susceptibles de valoración en una prueba son pertinentes (unos sí, otros no), ni todos los pertinentes lo son en la misma medida (unos más, otros menos); criterio cuya aplicación es más neta en los ámbitos técnicos que en los dominios del sentido común. De principio, por tanto, el decisor debe marcarse como objetivo mostrar que sus argumentos no solo son buenos sino mejores que los contrapuestos (un argumento a priori bueno pero que desmerece frente a otro se convierte en maloo $^{24}$ ). Es posible que por circunstancias variadas (haber sobrevalorado un método, pasar por alto discrepancias entre los propios especialistas, etc.) el decisor no logre el resultado perseguido. Pero eso se verificará después; no es algo que deba presuponerse de entrada. Bajar los brazos antes de empezar, concediendo que nos hallamos en un campo donde impera "la opinión de quien valora», entraña el riesgo de calificarlo ya como zona franca, libre de inspección (o de inspección limitada a reprimir solo actos de sabotaje: «error patente, craso, palmario»).

C. Y, curiosamente, si algo enseńa el seguimiento de los conflictos que genera el uso de la discrecionalidad técnica en materia de nombramientos

sentenza penale (controllo della)», Enciclopedia del Diritto. Aggiornamento IV, págs. 750-800 —pág. 763).

24 En el sentido de que, por ejemplo, la fluidez verbal (dato positivo en sí mismo) se convierte en un mal argumento para preferir, en un puesto de atención al público, a un candidato monolingüe que la posee frente a otro que la tiene en menor grado pero es trilingüe. 
(los del CGPJ me resultan más conocidos, y ellos estarán en mi cabeza) no es, desde luego, la intrínseca subjetividad de los argumentos (o sea, los fundados en la valoración de los variados méritos aportados por cada contendiente) que sustentan esta o aquella candidatura, sino la sonrojante ausencia de una comparación explícita, metódica y razonada de sus respectivos historiales, proyectos y ejercicios. No es por casualidad que en los recursos contra nombramientos del CGPJ se impugnen, no errores en la argumentación de los acuerdos, sino pura y llanamente falta (total o parcial) de motivación de los mismos. Dicho de otro modo: no es que se razone mal (o discutiblemente) el porqué, en orden a ocupar una presidencia de un Tribunal Superior de Justicia, el proyecto de actuación de un candidato que jamás ha participado en un órgano jurisdiccional colegiado pesa más que mil doscientos puestos de ventaja en el escalafón y veintitrés ańos de magistrada en varios tribunales de la otra competidora, simplemente no se razona.

Y las discusiones posteriores, ya en sede judicial, tampoco suelen incidir en el tipo de racionalidad exigible a los argumentos que han de justificar decisiones de ese o parecido tenor; consisten más bien en preámbulos divagantes (y sin retorno a tierra firme) sobre la diferencia entre un concurso de méritos y un nombramiento discrecional, sobre la valoración conjunta frente al baremo, sobre la dificultad de expresar lo percibido durante la comparecencia de los solicitantes y la convicción resultante, sobre si es obligatorio o no expresar la comparación entre los candidatos (y de todos o solo de los propuestos por la Comisión calificadora), sobre la relativizada valoración de los méritos jurisdiccionales para cargos con perfiles gubernativos, sobre el máximo grado de discrecionalidad en los nombramientos para plazas con funciones de gobierno, sobre la cambiante doctrina (y siempre genérica) que ha ido sentando la Sala $3^{\text {a }}$ en sus resoluciones, etcétera. En suma, cualquier cosa menos terminar hincando el diente en el asunto concreto y de manera precisa. Eso explica en parte, por ejemplo, el reciente espectáculo de una Sala $3^{\text {a }}$ perpleja (17 votos a favor, 15 en contra) a la hora de verificar si el CGPJ había ejecutado o no una resolución de la propia Sala (cfr. STS 1136/2017). ¡Hay que ver!

El excursus que antecede no persigue otra finalidad que subrayar la carencia de base empírica suficiente para asumir, al menos con carácter general e indiscriminado, que la elección y el manejo de criterios selectivos están condenados a padecer el inevitable y determinante influjo de la subjetividad de cada cual.

\section{A VUELTAS, UNA VEZ MÁS, CON EL «ERROR»}

Insisto en lo ya sugerido renglones atrás. La motivación de una decisión discrecional está para justificar ante el perdedor (al ganador le suele bastar con la victoria) que se ha hecho justicia, no para garantizarle a la postre que con 
él no se ha cometido por lo menos la flagrante injusticia de un «error patente, craso, palmario» (imenudo consuelo!).

¡Por cierto! Ese «error», aun vestido con ropajes tan ostentosos ("patente, craso, palmario»), puede resultar de complicada identificación, a menos de que se disipen antes algunas ambigüedades. Empiezo:

A. Un apunte de Sánchez Morón, tan pacífico y sensato como el de distinguir si hay o no "ostensibles diferencias entre los candidatos», da pie, sin embargo, a que se nos encienda una luz roja por el inciso que este autor introduce a continuación: «[...] salvo si se advierten ostensibles diferencias entre los candidatos, todo [la selección] depende de la opinión de quien valora sus ejercicios ${ }^{25}$ [cursivas mías].

De ahí parece desprenderse que, si las diferencias no son ostensibles, el decisor se halla enclaustrado en la jaula de oro de su personal subjetividad; por lo cual, haga lo que haga, su decisión jamás podrá ser tildada de patente o crasa o palmariamente errónea (y, de paso, se ahorrará todo esfuerzo en justificarla). De manera que, por exclusión, un error de tan apoteósica naturaleza solo podría caber en una situación de ostensibles diferencias entre quienes concursan.

Pero, aun si aceptáramos que así es, se alza rauda una pregunta: ¿cuál es el calibre para medir si una diferencia es o no «ostensible»: el de la magnitud (que la diferencia sea grande - por ejemplo, entre un aprobado raspado y un sobresaliente pletórico-) o el de la certeza (que sea indiscutible, incluso si pequeña - por ejemplo, entre un sobresaliente y una matrícula de honor; por ejemplo, por haber equivocado el nombre de un autor-) ? Pegunta a la que se agrega una segunda: ¿la existencia de esa diferencia ostensible es un dato de partida o un resultado al que se llega mediante algún razonamiento? Y una tercera como corolario de la anterior: ¿basta proclamar o es necesario justificar que hay o no hay una diferencia ostensible entre los participantes?

Son cabos sueltos que — seguro— no pillarán desprevenido a nuestro administrativista, pero que no deben soslayarse, so pena de que el planteamiento por él defendido sirva de cobertura a prácticas arbitrarias. ¿Cómo?

B. A poco que cualquiera se asome a los recursos que desembocan en la Sala $3^{a}$ encontrará inesperadas muestras de una misma estratagema para - con variable formulación- eludir el control judicial ${ }^{26}$. Y sintéticamente

25 Sánchez Morón (2015: 220).

26 Para algún detalle más, $c f r$. Igartua Salaverría, J. (2010), «El informe de la Comisión de Calificación. (Segunda anulación de otro nombramiento del CGPJ)», Revista Vasca de Administración Pública, 87-88, págs. $567-586$ (págs. 572-573). 
consiste: primero, en dar por sentada (sin descender a datos precisos) la sobrada aptitud de los candidatos para ocupar el cargo al que optan (por lo que no sería disparatado nombrar a cualquiera de ellos); y, segundo, en rebajar las posibles diferencias al rango de lo accesorio o a una cuestión de preferencias personales (o sea, llevarlo al terreno de la más exacerbada e infiscalizable discrecionalidad).

El argumento medular — falaz $z^{27}$ — se atisba a la legua: si todos los candidatos preseleccionados (en fase de calificación) ofrecen garantías para un desempeńo solvente del cargo al que aspiran, eso indica que entre ellos no existen diferencias sustanciales. Y así se explica que las propuestas de la Comisión del CGPJ — ahora la Permanente, creo- elevadas al Pleno suelan contener la nómina de los seleccionados por estricto orden alfabético, sin ninguna prelación entre ellos. Mise-en-scène ideal por tanto para — sea quienquiera el nombrado - tener por descartada (hasta por imposible, diría yo) la caída en un patente, craso y palmario error (impensable además — por si algo faltaraque pase inadvertido para la mayoría del Pleno).

De atmósfera no tan disímil respira algún otro plan para rasar cualquier pico que despunte por encima de un nivel a fin de equiparar a todos los candidatos seleccionados (y además con la anuencia de algún sector de la misma Sala 3a); como cuando, para primar el perfil gubernativo de la plaza judicial, neutralizando las interferencias que puedan provenir del desigual desempeño de funciones jurisdiccionales entre los candidatos, se postula llevar la comparación de esto último hasta "un razonable umbral de profesionalidad» nada más; criterio este de tan asombrosa elasticidad que podría servir de común denominador - entre, por ejemplo, los aspirantes a presidir un Tribunal Superior de Justicia - para una magistrada con veintitrés años de servicio en varias Audiencias cuanto para un candidato que jamás ha participado en un órgano colegiado. Y no son imaginaciones mías ${ }^{28}$.

27 Equivocación bien diagnosticada por Rodríguez de Santiago cuando distingue la irracionalidad en el resultado y la irracionalidad procedimental (Rodríguez de Santiago, J. M. (2016), Metodología del Derecho administrativo. Reglas de racionalidad para la adopción y el control de la decisión administrativa, Madrid-Barcelona-Buenos Aires-Sao Paulo: Marcial Pons, págs. 187-188). Distinción que, importada a nuestro terreno, podría traducirse así: aunque no es irracional nombrar a quien puede desempeñar bien una función, es irracional no nombrar a quien pudiera desempeñarla siquiera un poquito mejor porque acredita más méritos (y mejor derecho).

28 Es lo que se argumentaba, con base en las SSTS 29/02/2012 y 1/06/2012 de la Sección $7^{a}$, en el voto particular que diez magistrados de la Sala opusieron a la STS 1033/2016 del Pleno que anulaba un nombramiento del CGPJ. 


\section{4. ¿̇NOS HEMOS EXTRAVIADO?}

Hago un alto. Releyendo lo escrito y mirando hacia atrás, tengo la sensación de no haber topado con nada de lo que se nos había prometido. Se nos dijo: «Lo que verdaderamente importa no es la disputa teórica o conceptual, sino reflexionar cuál es la solución más correcta en casos como el que se plantea y en términos de justicia material ${ }^{29}$. ¿Qué hemos encontrado? Curiosamente, ninguna alusión al caso; solo teoría y conceptos, cuya conexión con el caso es, encima, desconocida o inexistente. $\mathrm{O}$ sea: por ningún lado se ve qué partido saca el profesor de Alcalá de tan ilustrativa (?) sentencia.

A. En efecto, salvo si se trata de una expansión autobiográfica de Sánchez Morón, ‘a cuento de qué viene aludir a la distinta valoración (objetiva o subjetiva, según) de lo actuado por los concursantes en función de si las diferencias entre ellos son o no ostensibles? En el caso que nos ocupa, nada sabemos de $s i$ había diferencias entre los candidatos, cuáles eran esas (si las había) y cómo eran (si ostensibles o no). Por lo que tampoco podemos conjeturar si y por qué una Comisión diversa quizás hubiera llegado a una valoración diferente.

B. Hay algo más radical todavía. Es que ni siquiera procede formular en términos de comparación (entre candidatos) el problema que llegó a la Sala. Era la calificación de un examen práctico individual lo que estaba en juego (y lo correcto de la puntuación obtenida, por debajo de la nota de corte - recuérdese-), con total independencia de los puntos que hubieran conseguido el resto de los participantes. La Comisión no se encontraba por tanto en el apremio de tener que seleccionar comparativamente a nadie frente a los demás.

C. Y se pasa por alto que se trataba de un examen escrito (eso sí, de lectura obligada ante la Comisión, como es de regla por si esta demanda algunas aclaraciones; cosa que no sucedió o no consta que sucediera). ¿Puede, entonces, afirmarse que "se encuentra más próximo a la realidad» quien (como la Comisión) oye la lectura de un texto, que quien (como en la Sala de justicia) tiene acceso a la lectura directa del texto? ¿Qué información relevante que adquiere la primera se le escapa en la segunda? Y, si en esta ocasión hubiera alguna, ¿`cuál pudo ser?

D. Aunque no era el caso, obviamente, las circunstancias cambian en un examen oral, cuya transcripción en un papel no permite apreciar la rapidez o

29 Sánchez Morón (2015: 219). 
lentitud en el enfoque de las respuestas, la seguridad o los titubeos en estas, ni la fluidez verbal en la formulación de las mismas, etcétera. Por lo que, ya con carácter general (plano en el que, de hecho, se mueve Sánchez Morón), no hay óbice para conceder, en línea de principio, que una Comisión conoce más datos y de manera inmediata, mientras que un Tribunal de justicia dispone de menos datos y solo mediatamente ${ }^{30}$.

A lo que debe sumarse otro rasgo distintivo capital: el órgano de selección está compuesto por «especialistas en la materia de que se trate, a diferencia (normalmente) del órgano judicial que controla su decisión». Lo cual arrastra una inexorable consecuencia: mientras el órgano de selección se vale de su específica preparación técnica, el órgano judicial cuenta con el auxilio nada más que de las genéricas reglas de la sana crítica.

Pues bien, el hondo calado de esos factores discriminatorios, que garantizan mejor el acierto del órgano de selección, contribuye a concluir en rigurosa lógica que, por contraposición, "probablemente [le] es más fácil equivocarse» ${ }^{31}$ al órgano judicial. Por lo que — cuestiona nuestro administrativista— «ipuede asegurar un órgano judicial que, en ausencia de elementos que demuestren un proceder arbitrario, el órgano de selección ha incurrido en un error y que el resultado justo del proceso selectivo debe ser necesariamente otro?» ${ }^{32}$.

La respuesta (negativa, claro) sería inapelable si la cuestión no estuviera creo- desenfocada. Es lo que intentaré mostrar.

\section{UN CONTROL ESPECÍFICO: 2̇«QUÉ» Y «CÓMO» CONTROLAR?}

Con reiteración he defendido ya en otros trabajos ${ }^{33}$, y sin nunca recibir por ello un tirón de orejas, el paralelismo entre — de un lado - el control judicial de la discrecionalidad administrativa y - de otro- el control casacional sobre la libre valoración de las pruebas en los tribunales de instancia. Ahora añadiré algo, buscando ceñir mejor la semejanza entre ambos controles: el control judicial es a la discrecionalidad técnica lo que el control casacional a la valoración de las pruebas periciales. Pues bien, a resultas de este par de

30 Sin embargo, no me parece apropiado decir que «los jueces no fallan sino en virtud de opiniones ajenas, sean de los abogados de las partes, sean las de los peritos» (pág. 221). No. Los jueces fallan (o deben fallar) en virtud de razones propias sobre el valor de las opiniones ajenas.

31 Sánchez Morón (2015: 221).

32 Sánchez Morón (2015: 220).

33 La última vez en J. Igartua Salaverría (2017), «Un curioso concepto de "motivación implícita” (Comentarios a la STS 420/2017)», Diario La Ley, 8986, págs. 1-10. 
hipótesis se perfilan los dos temas a considerar: el del objeto y el del método del control judicial sobre la discrecionalidad técnica. Iré por partes y paso a paso.

\section{1. ¿̇QUÉ SE CONTROLA? LA MOTIVACIÓN}

¿Existe no diré el riesgo, sino hasta la posibilidad de que el órgano judicial se atreva a dictaminar — como parece sugerir Sánchez Morón- que «el resultado justo del proceso selectivo debe ser necesariamente otro»? No lo creo. Y no tanto - aunque también- porque «el juez solo controla, no sustituye ni administra " ${ }^{34}$, sino porque el órgano administrativo y el órgano judicial no comparten el mismo ámbito material de actuación: uno es juez del procedimiento (selectivo), el otro es juez de la resolución (dictada por el primero):

A. Es decir, similar diferencia a la que, en lo tocante a la valoración de las pruebas, caracteriza - como alguien sostuviera ${ }^{35}$ - al tribunal de instancia (que es juez del proceso) y a la casación (como juez de la sentencia); en el sentido de que la casación no reactiva el proceso productivo del juicio, pues: 1) no adquiere pruebas; 2) no elabora hipótesis explicativas del hecho; 3 ) no selecciona el material probatorio; 4) no organiza ese material en una trama argumentativa completa y coherente; 5) no decide.

Parecido, pues, a lo que sucede con el control judicial de la discrecionalidad administrativa, en el que: 1) el tribunal de justicia no organiza la recopilación de datos, informes, dictámenes, etc., que luego conformarán el expediente; 2) no elabora hipótesis acerca de cuál sea la actuación más idónea para conseguir, en un contexto dado, una determinada finalidad; 3) no valora el material compilado en el expediente, seleccionando el pertinente y desechando el intempestivo, ni establece preferencias dentro del material seleccionado; 4) no inserta el material pertinente y preferido en un entramado argumental, completo y coherente, en orden a mostrar que tal o cual decisión es la mejor; 5) finalmente, tampoco decide ${ }^{36}$.

34 D. J. Sesín (2012), «El juez sólo controla. No sustituye ni administra. Confines del derecho y la política», Revista de Direito Administrativo y Constitucional, 47, págs. 51-84.

35

coviello (2000: 782).

Afirmación que no ponen en entredicho situaciones en las que la casación, lejos de limitarse a ordenar una retroacción de actuaciones a fin de que la Administración emita una nueva calificación o una nueva propuesta, sustituye la decisión del órgano administrativo con la suya propia; ya que ninguna de aquellas situaciones pueden ser conceptuadas como amparadas por la «discrecionalidad»: en efecto, no es discrecionalidad, sino arbitrariedad, excluir de la denominación de origen una parte del territorio que reúne exactamente las mismas características físicas que el resto incluido 
B. Circunscrito ya a la sentencia (del tribunal de instancia) o a la resolución (del órgano administrativo) el objeto del control que me ocupa, sin embargo no acaban ahí los recortes.

En el documento de una sentencia (o de una resolución administrativa razonada) se distinguen dos partes: el acuerdo (decisión) y la argumentación (motivación), abriéndose así la posibilidad a un doble control: sobre la decisión y/o sobre la motivación.

Ahora bien, las decisiones pueden ser de dos clases: unas están jurídicamente regladas (por ejemplo, las atinentes a la interpretación de los textos legales) y otras no están sujetas a reglas de esa naturaleza (por ejemplo, las relativas a la libre valoración de las pruebas, o al ejercicio de la discrecionalidad administrativa).

De su lado, la motivación está legalmente prescrita con carácter general; es decir: con independencia de si la decisión sea o no reglada. Y no tendría sentido imponer una motivación obligatoria si después no se ejerce ningún control procesal sobre ella ${ }^{37}$.

Dicho esto, la especificidad del control judicial aquí pertinente (en mi opinión) determina que su ejercicio, en el caso de las decisiones no regladas, recaiga nada más que sobre su motivación.

C. Una vez confinado en la motivación el ámbito del control, hemos de reparar en que, sin embargo, la motivación carece de autonomía funcional. No es una «mónada» que permita ser examinada «en sí y por sí sola " ${ }^{38}$; por tanto, la racionalidad de la motivación no es de carácter autorreferencial nada más (racionalidad como coherencia intrínseca), sino, ante todo, relaciona ${ }^{39}$.

En efecto, hay una doble circunstancia que condiciona la hechura de la motivación. Por un lado, la sentencia o resolución consta de dos elementos articulados entre sí: decisión y motivación. Por otro, la sentencia o resolución se emite como colofón de un proceso o procedimiento y, por ende, guarda con

dentro de la delimitación impugnada; no es discrecional, sino equivocado, eliminar a una aspirante a un puesto sanitario por haber cometido un "error conceptual grave», siendo así que el tratamiento indicado por ella era el habitual y exitoso en el hospital donde trabajaba; no es discrecional, sino erróneo, eliminar a un aspirante cuando las preguntas del test admitían también las respuestas dadas por aquel, etcétera. Estos y otros ejemplos jurisdiccionales pueden verse en Fernández (2015: 222-227). «Decidir» discrecionalmente es optar entre dos o más alternativas razonables. Si solo cabe una solución razonable, no hay opción; entonces tampoco lugar para la decisión.

37 Iacoviello (2000: 781).

38 Iacoviello (2000: 787).

39 Iacoviello (2000: 788). 
este un vínculo ${ }^{40}$. De ahí se sigue la relación doble de la motivación: ad intra de la sentencia o resolución (con la decisión, para justificar por qué esta es correcta) y ad extra de la sentencia o resolución (con el proceso o procedimiento, para asegurar el enlace de aquella con este). Entonces, por fuerza de las cosas, en la motivación habrán de ser identificables dos contenidos: uno informativo (indicando todos los elementos producidos durante el proceso o procedimiento y que son relevantes para la decisión) y otro netamente argumentativo (construyendo con aquellos elementos un discurso orientado a justificar la decisión adoptada). Obviamente, las relaciones de la motivación con — por arriba- la decisión y con — por abajo- el proceso o procedimiento no deben inducirnos a olvidar que la motivación ha de tener en sí misma una consistencia lógica — sensu largo- en cuanto discurso racional.

Dicho esto, quedarían perfiladas las tres referencias para ejercitar un control sobre la motivación: primera, la de su relación con la decisión adoptada (censurándola si no justifica lo que se ha decidido o si justifica menos de lo decidido); segunda, la de su relación con los elementos que proporciona el proceso o procedimiento (examinando si se inventan o se tergiversan o se omiten datos relevantes); tercera, la de su relación consigo misma, si así cupiera hablar (detectando en el discurso — si las hubiera - contradicciones lógicas, aseveraciones incompatibles con las ciencias, falsas máximas de experiencia, inferencias ausentes, etc.).

En síntesis, controlar la motivación supone verificar: a) la completitud de la justificación que aporta; b) la fidelidad de la información en la que se basa; c) la racionalidad de la argumentación construida.

D. Tras este dilatado interludio teórico-conceptual, cabe extraer un par de enseńanzas que se proyectan en perpendicular sobre el tema que estoy debatiendo.

La primera y más evidente: que si el órgano judicial (aquí contemplado) es juez de un texto (resolución administrativa en nuestro caso) y no de una suceso real (por ejemplo, la competición entre postulantes a un cargo), resulta innecesario el conocimiento adquirido in situ relativo a lo acontecido en el procedimiento selectivo. Para controlar la motivación de una resolución administrativa — siempre a instancia de parte, claro— bastará cotejarla con la información obrante en el expediente administrativo.

40 Pues, ¿qué sentido tendría examinar, por ejemplo, si un juez ha motivado bien o mal la valoración de unas pruebas que: o no se han producido dentro del proceso, o son una tergiversación de las pruebas producidas, o no están todas las pruebas decisivas? ¿De qué aprovecha controlar la racionalidad de una motivación si esta empezara por no respetar lo que ha ocurrido en el proceso, inventándose pruebas inexistentes o escamoteando o manipulando pruebas existentes? 
La segunda: el control de la motivación implica, quiérase o no, un control siquiera indirecto pero interino sobre la decisión. Control indirecto, porque al no ser posible jurídicamente una motivación correcta de una decisión equivocada $^{41}$, la motivación incorrecta funciona como síntoma de una decisión errónea. Control interino, porque siendo posible una decisión acertada, aunque mal motivada, no se excluye que el síntoma se quede en un falso positivo (así que habría de esperarse a que el órgano decisor o bien motive adecuadamente la decisión — si es eso viable — o bien cambie la decisión).

$\mathrm{Y}$, de ese modo, se esquivan dos insidias: una, impidiendo que prospere una decisión bajo sospecha; otra, impidiendo que, a través del control sobre la motivación, el órgano judicial decida por su cuenta ${ }^{42}$.

E. Claro que, aun si valieran las precedentes reflexiones, se objetará que el control sobre la «motivación» estaría condenado a naufragar porque, esta vez, el órgano judicial no disponía de instrumentos adecuados para ese fin.

Precisemos. El disenso entre las explicaciones que ofreció la Comisión examinadora para justificar el «suspenso» de la candidata y las alegaciones (del perito) de la recurrente para fundamentar la corrección del ejercicio realizado, a fin de cuentas ponía en entredicho a la motivación de la decisión adoptada (o sea: jestaba esta convenientemente razonada?). Ahora bien, dada la naturaleza técnica de la motivación (que justifica con razones médicas la calificación negativa en un examen práctico de medicina), ¿qué legitimidad racional para controlarla posee un órgano judicial carente de la preparación específica en la materia? Objeción que, en principio, alcanzaría - entiendo- a cualquier tribunal de justicia, de todas todas; es decir: al margen del resultado (positivo o negativo) de su control; pues tan incapacitado estaría para decir tanto una cosa (que las alegaciones de la recurrente justificaban el acierto del examen) como la contraria (que tal réplica no demostraba ningún grave error en las explicaciones ofrecidas por la Comisión examinadora).

Cuestión de entidad sobrada como para merecer un apartado separado, el que sigue.

\section{2. ¿̇COMO SE CONTROLA? EL PAPEL DE LA «SANA CRÍTICA»}

Retornando al contencioso que hubo de resolver la Sala $3{ }^{\text {a }}$, la descripción del desacuerdo que se nos proporciona en su sentencia es de una notable miseria. Penuria de datos sustanciales de difícil remedio, por tanto, para quien asuma el comentario de la misma, empezando por Sánchez Morón. O sea, la culpa no es suya.

41 Iacoviello (2000: 788).

42 Iacoviello (2000: 785). 
Pero ese hándicap aborta su proyecto de presentarnos esta STS a modo de test práctico para dirimir un desencuentro entre posiciones teóricas discrepantes, pues como mucho solo le sirve de pretext para reiterar su partidaria postura teórica (respetabilísima, sin duda).

Lo cual, pese a todo, no obsta a que la cuestión de índole general por él formulada fuera pertinente, siquiera como telón de fondo, para rentabilizar las lecciones (si las hubiera) que se derivan de ese caso particular (de cuyo detalle repito- no hay noticia). Y, de todos modos, esta cuestión generalista tiene en sí misma una enjundia que bien merece la cortesía de una autónoma consideración.

En sustancia: si la consistencia del juicio técnico hubiera de ser valorada en «aplicación de las "reglas de la sana crítica" a las que la legislación de ayer y hoy apela ${ }^{43}$ - tesis que también se acoge en el punto $2^{\circ}$ del VP-, ¿no significa eso eliminar el margen de apreciación técnica, reconocido a la Administración, «a favor de la también llamada sana crítica, que de hecho no supone sino sustituir una opinión de especialistas o expertos en cada materia por otra opinión de quien no lo es?» ${ }^{44}$. Pues no. Y es lo que intentaré argumentar:

A. De entrada, creo que bajo ningún concepto el uso de la "sana crítica» entraña el riesgo de sustituir la opinión del técnico por la opinión de quien no lo sea; por la abrumadora razón —y pido excusas por bisar la canción de antes - de que el órgano administrativo y el órgano judicial acometen tareas diferentes y sobre objetos distintos. Al uno le toca decidir en un proceso de selección; al otro le corresponde controlar la racionalidad de lo argumentado por el primero a favor de su decisión. No hay miedo, pues, de que el segundo suplante (sustituya) al primero.

B. Conquista pírrica nada más si no fuera porque tal aclaración nos franquea la entrada a una cuestión muy prometedora. La que sigue.

No tiene vuelta de hoja que, en materia científico-médica, decidir sobre el acierto o desacierto de un examen práctico requerirá alguna ristra de juicios técnico-científicos. Pero — aquí viene la pregunta— ¿acaso controlar la lógica de un juicio técnico exige el uso de un juicio de igual naturaleza técnica que el juicio controlado? No necesariamente —es la respuesta-. Porque una cosa son los conocimientos (de carácter científico o técnico) sobre la realidad analizada, y otra muy distinta los criterios (de orden epistémico) para valorar aquellos conocimientos adquiridos ${ }^{45}$.

43 Fernández (2015: 222).

44 Sánchez Morón (2015: 222).

45 Cfr. C. Santoriello (2012), «Il ruolo degli esperti nel proceso penale fra consulenze di parte e perizia ex officio», en M. Montagna (coord.), L'assassinio di Meredith Kercher. 
Procede advertir que reverdece aquí la aparente paradoja del iudex peritus peritorum (el juez inexperto que zanja el desacuerdo entre dos peritos expertos), pero a la que los estudiosos de la prueba procesal ya le han encontrado una convincente salida ${ }^{46}$; particularmente tras la archifamosa Sentencia del caso Daubert (Corte Suprema de los Estados Unidos, 1993). En la opinion del juez Blackmun, curiosamente, se asignaba al juez la función de gatekeeper para discriminar, de entre los variados informes periciales que llegaban a los tribunales, los atendibles de los que no lo eran. Y, al efecto, proponía la observancia de unos criterios resumibles así: a) si la teoría o metodología o técnica en cuestión había sido sometida o no a procedimientos de corroboración y falsación; b) si se conocía o no la tasa de error de la teoría o metodología o técnica cuestionada; c) si la referida teoría o metodología o técnica había gozado o no de difusión en publicaciones acreditadas; d) si tal teoría o metodología o técnica concitaba o no una aceptación generalizada entre los especialistas en la materia.

Criteriología concreta quizá discutible (al menos ya ha sido parcialmente objetada) y apta para unas determinadas ramas de la ciencia y no tanto para $\operatorname{otras}^{47}$, pero que, no obstante, muestra la posibilidad de ejercer un control racional «sobre opiniones de especialistas o expertos en cada materia» por quien no lo es, pese al recelo manifestado por nuestro administrativista.

C. Como un ejemplo vale más que mil palabras (¡lástima que nos falte información sobre el que aquí tocaba!) y aburre menos, me valdré de uno muy apto — creo - para ilustrar lo que persigo. Me refiero al — muy aireado en la prensa internacional ${ }^{48}$ — caso Amanda Knox (por el asesinato de Meredith Kercher), en el que la acusación también implicó como coautor al novio de la primera, Raffaele Sollecito. La prueba principal contra este consistía en el ADN hallado en la presilla del sujetador de la víctima, cortada a navaja; pedacito avistado (y fotografiado) en el lugar del crimen ya desde la primera inspección, pero desatendido hasta su recogida 46 días más tarde (circuns-

Anatomia del proceso di Perugia, Roma: Aracne, págs. 221-236 (págs. 230-231). Dicho de otro modo: el juez no debe sustituir al experto para desarrollar de nuevo la actividad que este ya ha realizado y expresar su propio parecer, pues no puede transformarse en un especialista de este o aquel ramo del saber. Lo que se pide al juez es efectuar un control sobre la atendibilidad de lo que el experto expone (M. Taruffo (2016), «La prova scientifica. Cenni generali», Ragion Pratica, 47, págs. 335-354 — pág. 347). Como he sugerido en la nota precedente y espero explicitarlo mejor en párrafos sucesivos.

47 Sobre todo ello, cfr. Taruffo (2016: 338-342).

48 Porque a la truculencia del suceso se ańadían los azarosos avatares del periplo procesal del caso (que pasó por las manos de hasta cinco tribunales distintos). 
tancia que para la policía científica no entrañaba riesgo razonable de posible contaminación de la muestra, dado que la casa estaba precintada, que los rastros genéticos no «vuelan» de un objeto a otro y que el agente que recogió el trocito llevaba guantes sin estrenar). Pues bien, el fundamento racional de la correspondencia (entre el ADN detectado en la muestra y el perfil genético de Raffaele) establecida por los genetistas de la acusación (y contestada por los de la defensa) fue finalmente desestimado por la Corte di Cassazione, y sin que esta tuviera que bracear entre los remolinos de disquisiciones técnicas. ¿Con qué razones, entonces? $\mathrm{Al}$ menos con las cuatro siguientes ${ }^{49}$ :

a) la primera: de ningún modo se observaron las reglas metodológicas, reglas de la experiencia en materia de recogida y conservación de las muestras, consagradas en los protocolos internacionales. No puede descartarse, por tanto, la contaminación del trocito de sujetador porque: 1) entre el momento de su detección y el de su recogida (mes y medio más tarde), hubo otras entradas de los investigadores, los cuales registraron por todas partes, moviendo muebles y objetos, a la búsqueda de más elementos probatorios; 2) la presilla fue probablemente pisada (aparecía aplastada) y se encontraba a metro y medio de donde fue vista la primera vez, y 3 ) en el momento de su recogida (que fue filmada por la propia policía) se comprueba que la presilla fue pasando de mano en mano entre investigadores, algunos de los cuales llevaban guantes de látex usados en el registro de otras dependencias de la casa.

b) La segunda: el uso de un método, viciado por el sesgo sospechocéntrico, en el cotejo entre el ADN de la muestra y el ADN de Raffaele. Es decir, en lugar de reconstruir el perfil genético hallado en la muestra y compararlo después con el del imputado (según prescribe la comunidad científica), se procedió al revés; inversión gravísima cuando - como así ocurrió — había en la presilla una mixtura de rastros biológicos pertenecientes a varios varones (no el simple de un sujeto implicado), no siendo nada fácil identificar el perfil genético de a quién correspondía cada uno de aquellos. Por eso, el ADN de Raffaele sirvió de guía para recomponer el puzle y obtener así un perfil genético que fuera compatible con aquel. Ahí estuvo la desviación.

c) La tercera: dada la baja concentración de $\mathrm{ADN}$ en el material biológico hallado, habrían de efectuarse dos (si no hasta tres) amplificaciones del mismo, como disponen los protocolos internacionales (pues en la segunda amplificación pueden aparecer elementos no detectados en la primera y viceversa). Sin embargo, los genetistas de la policía científica realizaron solo una amplificación.

49 Expuestas con más detalle en M. D'Elia (2010), Il delitto di Perugia. L'altra verità, Milano: RCS Periodici, págs. 107-115; y, sobre todo, P. Tonini y D. Signori, (2016), "Il caso Meredith Kercher», en C. Conti, Processo mediatico e processo penale, Milano: Giuffrè, págs. 135-180 (especialmente págs. 161-167). 
d) La cuarta: cuando la adquisición de un elemento probatorio no es susceptible de repetición, el dato conseguido carece de validez científica al no haber sido sometido a los procesos de verificación y falsación. Pues bien, puesto que los ganchitos de la presilla se encontraban cubiertos de una costra, producida seguramente por la oxidación de las sales empleadas en su extracción y por elementos herrumbrosos del metal mismo, los peritos de la defensa no tuvieron opción para un contra análisis.

En suma: la Corte di Cassazione no corrigió los resultados de los genetistas de la policía. Y, aun menos, tampoco los sustituyó por otros distintos. ¿Acaso estableció la Corte que no era de Raffaele el ADN analizado? No, solo dijo que no estaba probado correctamente que lo fuera. Reconoció los límites del control judicial.

Los criterios con los que se acreditan o invalidan conocimientos sobre la realidad funcionan, respecto de estos, como un metadiscurso (discurso de segundo grado); esto es: se sitúan en distinto nivel. Así no hay riesgo de que se solapen.

D. Y ¿qué decir de las reglas de la sana crítica? Que suelen ser muy mencionadas pero poco estudiadas ${ }^{50}$. Situación que tampoco aquí será remediada. No obstante, alguna cosa indispensable deberá comentarse.

Pues bien, las reglas de la sana crítica se inscriben en el ya señalado ámbito de los criterios, no en el de los conocimientos sobre las cosas. La sana crítica no nos enseña si la Tierra gira alrededor del Sol (eso incumbe a la astronomía) o si en una relación sexual no consentida la víctima siempre muerde y araña al agresor (asunto reservado a la observación de los comportamientos humanos); pero nos ofrece pautas para juzgar criticamente por qué el primer aserto tiene fundamento científico y por qué el segundo se basa no en una máxima de experiencia sino en una inexperiencia máxima ${ }^{51}$.

O sea: la "sana crítica» no es un compendio de todos los saberes (los provenientes de las ciencias, de la experiencia cotidiana, de la psicología...), como no pocas veces suele pensarse. Pero tampoco un sucedáneo (similar al de las tortas a falta de pan) para que un amateur (el juez) tercie con un mínimo decoro en las disputas entre profesionales poniendo el stop siquiera ante un

50 Hubo que esperar a fecha reciente para disponer de la primera (y única, creo) monografía dedicada a institución procesal tan arraigada en nuestra tradición jurídica, cual es la de X. Abel Lluch (2015), Las reglas de la sana crítica, Madrid: La Ley.

51 Pese a que suela asumirse lo contrario, las «máximas de experiencia» no forman parte de las reglas de la sana crítica. La sana crítica nos provee de «reglas» sobre la formación, la formulación, la clasificación, el valor y el uso de tales máximas. Pueden encontrarse algunos ejemplos en Abel Lluch (2015: 101-107). 
disparate (o «error manifiesto»), según he creído advertir en el autor aquí criticado. Eso por un lado.

Por otro, como no existe una racionalidad ahistórica e inmutable, tampoco hay un depósito invariable de reglas de la sana crítica sino un flujo (cada vez más caudaloso y diversificado) de ellas. De ahí que los criterios de la sana crítica, en cuanto expresión de una progresiva y laboriosa racionalidad, no los llevemos inscritos en nuestras neuronas ni los interiorizamos absorbiéndolos del medio ambiente social por ósmosis natural. Y todavía menos tratándose de las reglas críticas que la epistemología va destilando a partir del incesante desarrollo de los conocimientos científicos y técnicos. Lo cual, claro está, también «implica una transformación significativa de la preparación que el juez debe tener: lo que el juez necesita para efectuar sus valoraciones sobre la prueba científica son las nociones de método y los conocimientos epistemológicos adecuados para realizar efectivamente los controles de los que se ha hablado"; sin tales herramientas, se encuentra ante el dilema de o bien prestar un «asentimiento acrítico» a la opinión del perito (o del órgano técnico), o bien formular un propio "disenso igualmente acrítico" ${ }^{52}$.

Recapitulando: las reglas de la sana crítica son un arma de doble filo. Sirven al juez para controlar un objeto (por ejemplo, el acuerdo de un órgano administrativo), pero también de control sobre si el sujeto que controla (o sea: el propio órgano judicial) maneja o no una suficiente «cultura de criterios»" ${ }^{53}$.

Ahora bien, la cabal acreditación tanto de lo uno como de lo otro se hace factible solo si la sentencia está debidamente motivada. ¿Ha satisfecho tal requisito esta STS de la Sala 3a?

52 Taruffo (2016: 348), en el mismo sentido, Abel Lluch (2015: 114-116). Ya hace una docena de ańos denunciaba esa grave deficiencia en nuestros tribunales el clarividente magistrado J. Hernández García (2005), «Conocimiento científico y decisión judicial. ¿Cómo accede la ciencia al proceso y cómo puede valorarse por los jueces?», Jueces para la Democracia, 54, págs.73-81.

53 En expresión de Santoriello (2012: 230). 
